\title{
Internal Pudendal Artery Angioplasty to Rescue Penile Gangrene.
}

\author{
Pratik Shah $^{1}$ Vimal Someshwar ${ }^{1} \quad$ Krishna Mundada $^{2}$ Santosh Waigankar ${ }^{3}$ \\ ${ }^{1}$ Department of Radiology, Kokilaben Dhirubhai Ambani Hospital and \\ Medical Research Institute, Mumbai, Maharashtra, India \\ ${ }^{2}$ Dr. R.N. Cooper Hospital, Mumbai, Maharashtra, India \\ ${ }^{3}$ Department of Urooncology, Kokilaben Dhirubhai Ambani Hospital \\ and Medical Research Institute, Mumbai, Maharashtra, India \\ Address for correspondence Krishna Mundada, Final Year MBBS, H.B. \\ T. Medical College and Dr. R.N. Cooper Hospital, JVPD Scheme, Juhu, \\ Mumbai, Maharashtra, 400056, India \\ (e-mail: mundadakrishnavinod29@gmail.com).
}

J Clin Interv Radiol ISVIR 2022;6:150-151.

\author{
Abstract \\ Keywords \\ - penile gangrene \\ - internal pudendal \\ artery \\ - angioplasty
}

Internal pudendal artery (IPA) is a branch of internal iliac artery that mainly supplies the perineal organs and external genitalia. Any obstruction in the artery seen in diabetics, hypertensives, or chronic kidney disease-induced calciphylaxis leads to decreased blood flow and may cause gangrene. IPA angioplasty is a known therapeutic procedure for erectile dysfunction and has shown promising results. However, similar procedure to relieve arterial blockade may be used to stop spread of penile gangrene and save the anatomical and physiological functions of the penis. We report a novel case of IPA angioplasty in patient of penile gangrene to circumvent total penectomy.

\section{Case Description}

A 63-year-old male, a known case of hypertension, diabetes mellitus, and chronic kidney disease with a history of penile circumcision for phimosis 15 days back, came with severe ischemic pain, dysuria, glans abscess, and gangrene of glans penis. The vitals of the patient were in normal range. After thorough examination of the patient, a likely arterial obstruction was suspected to be the cause of gangrenous changes in the organ. Bilateral IIA angiogram (digital subtraction angiography) was performed that showed multisegment focal stenosis of right internal pudendal artery (IPA; - Fig. 1A) and hypoplastic left IPA with occlusion of distal branches (-Fig. 1B).

Technique: The stenotic segment was negotiated with Progreat microcatheter $2.9 \mathrm{Fr} / 130 \mathrm{~cm}$ (Terumo, Somerset, New Jersey, United States) and over Fielder FC wire 0.014" (Asahi Intecc, Nagoya, Japan), balloon angioplasty 1 x $10 \mathrm{~mm}$ Artimes balloon (BrosMed, United States), and 1.5 X $12 \mathrm{~mm}$ Mini trek balloon (ABBOTT, United States). The final angiogram showed good flow across the stenotic segment into the

received

April 10, 2021

accepted

June 9, 2021

published online

September 1, 2021
DOI https://doi.org/ $10.1055 / \mathrm{s}-0041-1732798$ ISSN 2457-0214. distal circulation (-Fig. 1C). The patient was started on $150 \mathrm{mg}$ of Ecosprin and $75 \mathrm{mg}$ of clopidogrel. There was relief of pain following the angioplasty.

The patient was monitored for the next few days and a partial penectomy was performed under aseptic measures. An incision at the corona of the penis showed mild bleeding and hence decision to retain the penis for normal excretory function and lifestyle of the patient was taken. The cut section of urethra and corpora cavernosa showed minimal bleeding. Reconstruction of the penis was done using Vicryl suture (-Fig. 2). Complication corner: None.

\section{Discussion}

Complete necrosis of any tissue can lead to gangrene. Dry gangrenes are caused due to occlusion of blood vessels supplying the tissue and are usually associated with chronic systemic disorders like diabetes and hypertension that lead to degenerating, atherosclerotic changes along with extensive calcification in arteries. Calciphylaxis seen with endstage renal disease is also a known cause of small vessel

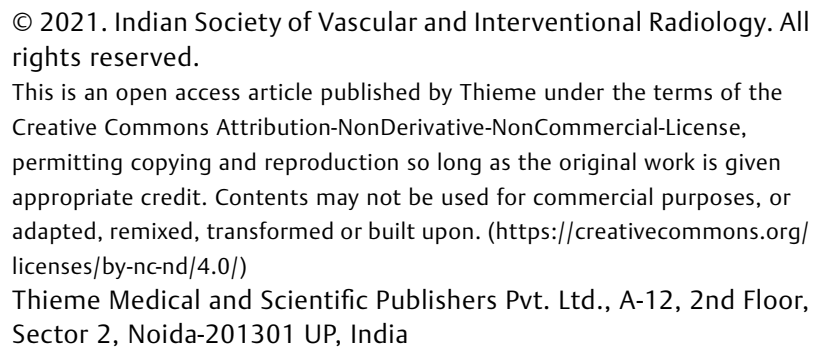

(C) 2021. Indian Society of Vascular and Interventional Radiology. All rights reserved.

This is an open access article published by Thieme under the terms of the Creative Commons Attribution-NonDerivative-NonCommercial-License, permitting copying and reproduction so long as the original work is given appropriate credit. Contents may not be used for commercial purposes, or adapted, remixed, transformed or built upon. (https://creativecommons.org/ licenses/by-nc-nd/4.0/)

Thieme Medical and Scientific Publishers Pvt. Ltd., A-12, 2nd Floor, Sector 2, Noida-201301 UP, India 

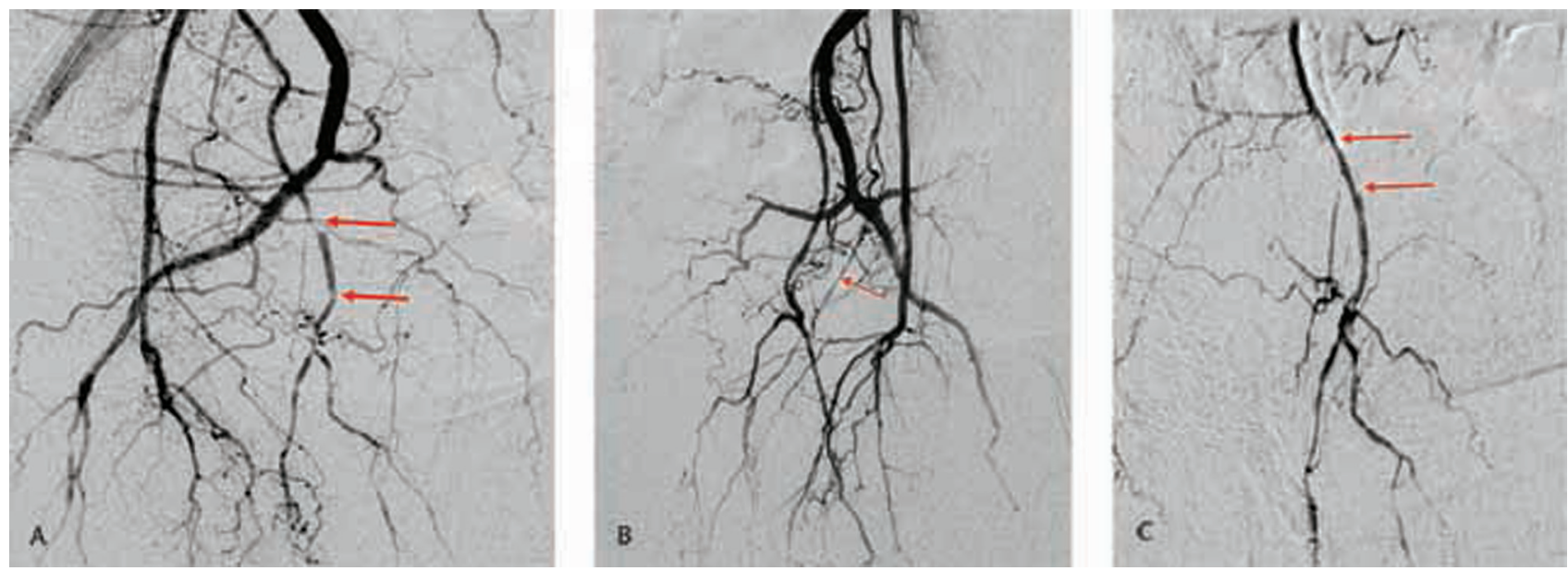

Fig. 1 (A) Angiogram showing multisegment focal stenosis of right internal pudendal artery. (B) Left IIA angiogram showing hypoplastic left internal pudendal artery. (C) Post angio plasty, good flow is seen in sight pudendal artery.

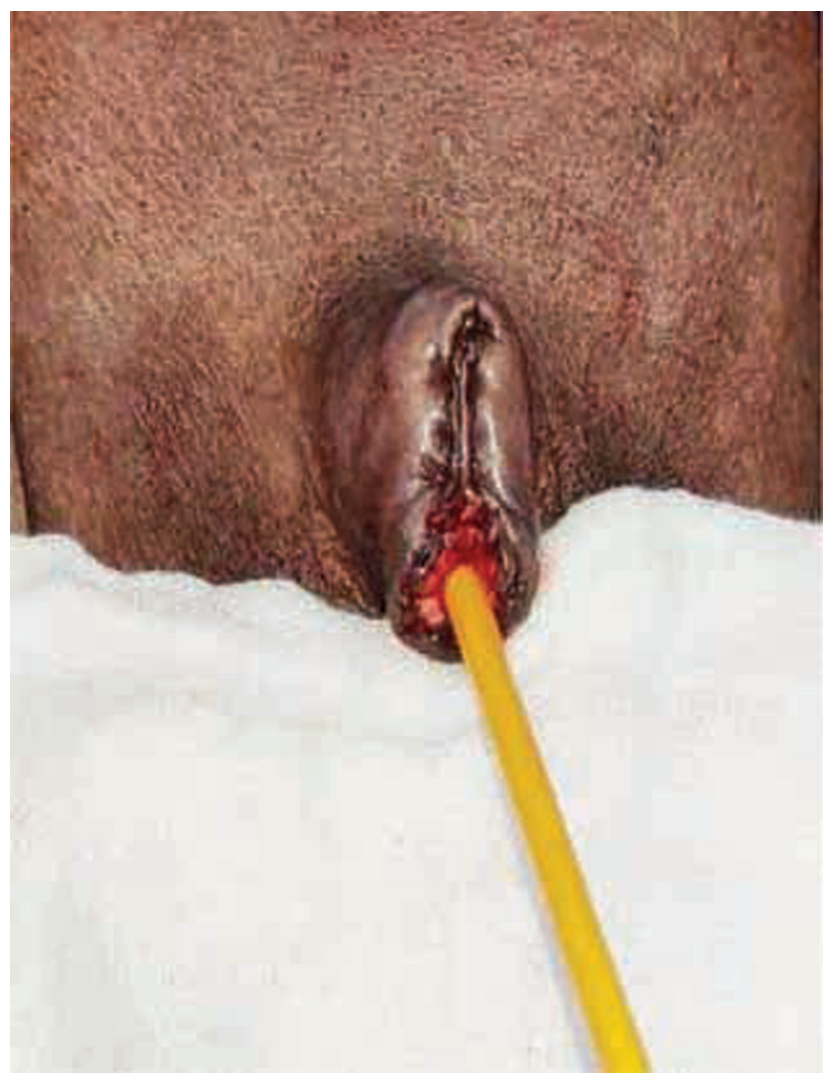

Fig. 2 Postoperative image showing intact urethra and catheter insertion.

occlusion and ischemia of tissues. ${ }^{1}$ The patient being reported had all the three comorbidities most likely contributing to severe decrease in penile blood flow.

Gangrene of the penis due to arterial occlusion is not a very common condition. It is seen with severe peripheral vascular diseases and has high mortality rates especially when associated with chronic kidney failure. ${ }^{2}$ Diagnosis of the arterial occlusion causing penile gangrene is not well studied and relies mainly on patient history and physical examination; very few reports mention use of angiography for such purposes. ${ }^{3}$ Angioplasty has been used successfully for the treatment of ischemic erectile dysfunction; however, the use to conserve gangrenous glans has limited information. ${ }^{4}$ This case report mentions use of angiography to detect multifocal calcifications and atherosclerosis of right IPA in the patient with hypoplastic left IPA and is the first reported case of use of IPA angioplasty for penile conservation.

Penile necrosis involves amputation of the organ; this may avoid further spread of gangrene temporarily but does not treat the underlying cause of ischemia thus leaving behind chances of recurrent gangrene in case of partial penectomy. Procedures like total penectomy prompts repeated suprapubic catheterization for the patient that may further contribute to recurrent infections, morbidity, mortality in such patients, not to mention the impairment of lifestyle. ${ }^{5}$ Our case report describes a more conservative treatment involving alleviation of obstruction via angioplasty of the IPA that helped conserving the anatomy of the penis and its function and desist total penectomy. Early treatment and continuous monitoring of the patient helped preserving $2 \mathrm{~cm}$ shaft of the penis.

Conflict of Interest

None.

\section{References}

1 Agarwal MM, Singh SK, Mandal AK. Penile gangrene in diabetes mellitus with renal failure: a poor prognostic sign of systemic vascular calciphylaxis. Indian J Urol 2007;23(02):208-210

2 Singh V, Sinha RJ, Sankhwar SN. Penile gangrene: a devastating and lethal entity. Saudi J Kidney Dis Transpl 2011;22(02):359-361

3 Camacho J, Grand R, Blevins N. Sharma P, de Riese W, Cammack J. Occlusion of bilateral dorsal penile arteries resulting in glans necrosis in an obese male truck driver. Radiol Case Rep 2018;13 (02):397-399

4 Shiraki T, Iida O, Okamoto S, Ishihara T, Fujita M, Uematsu M. Usefulness of endovascular therapy for penile gangrene secondary to calciphylaxis: a case report. Ann Vasc Surg 2015;29(07):1451. e11-1451.e15

5 Stein M, Anderson C, Ricciardi R, Chamberlin JW, Lerner SE, Glicklich D. Penile gangrene associated with chronic renal failure: report of 7 cases and review of the literature. J Urol 1994;152(6 Pt 1)2014-2016 